First publ. in: Negotiating adolescence in times of social change I

Lisa J. Crockett and Rainer K. Silbereisen (eds.). Cambridge:

Cambridge University Press, 2000, pp. 58-68

\title{
Effects of Social Change on Individual Development: The Role of Social and Personal Factors and the Timing of Events
}

\section{Gisela Trommsdorff}

Social change can be a gradual unfolding of different ways of life or can imply a sudden, fundamental transformation of economic, social, and political institutions, as was the case in Eastern Europe after the end of the Cold War. Individuals perceive, experience, and handle effects of social change on the basis of certain sociopsychological processes. This chapter focuses on how individuals deal with social change - how social change is perceived, experienced, and acted upon by the person and how these reactions affect human development.

Until recently, social change and individual development were studied separately in different disciplines. Attempting to relate these two complex topics of research may increase the risk of failing to deal successfully with either one. However, I believe that the study of individual development in a changing socioeconomic context will allow us to further our understanding of human development. This belief is based on the assumption that individual development is an active process taking place over the life course in multiple contexts. The active role of the individual is seen in the psychological processes of negotiating the self in relation to the environment, including goal setting, decision making, and behavior. The contextual view enlarges the individual-centered approach by specifying ecological conditions that affect individual development and by illuminating multidirectional processes in changing person-environment relations.

When dealing with the possible effects of social change on individual development, several issues have to be clarified:

1. Which aspects of social change have an impact on the individual person?

2. How is the individual person affected by such factors?

3. Why do some people gain from social change and others experience losses?

4. How does the outcome of social change affect further individual development?

From a theoretical perspective, the questions are, Can the view of development as an active, life-long process-in-context further our understanding of individual

Parts of this research were supported by the Deutsche Forschungsgemeinschaft (AZ $\operatorname{Tr} 169 / 5-1$; 5-2). 
development in periods of social change, and, Can this approach bridge two very different phenomena: social change and individual development? To begin to address these questions, contextual factors and dimensions of subjective experience will be discussed. Each is discussed in relation to the other according to a goodnessof-fit model.

Social change can induce significant modifications in the person's environment. However, these changes are only relevant for the person's further development if demands for certain behavior in the (new) environmental setting do not fit the person's psychological and social resources. Depending on the person and his or her environment, certain social changes may imply either stressors and risk factors or new options and opportunities for development. The person can experience environmental changes in such a way that previously successful goal attainment is blocked, or previously unattainable goals can now be reached. Internal processes of evaluating such experienced environmental change may induce cognitive and socioemotional reorientation: Previous goals are modified or abandoned, and this is followed by a restructuring of one's goals, active planning, and decision making. In this way social change stimulates individual development.

Socioeconomic changes such as economic hardship thus do not necessarily mean a stressful life event but could mean a challenge stimulating the person to engage in coping strategies that later lead to developmental gains in options and resources. This can be seen from Elder's (1974) famous study Children of the Great Depression. Girls and boys and children of different developmental ages experienced this social change in very different ways, some gaining and some losing from economic hardship. The differing outcomes were due to the ways in which contextual factors and previously established social and personal resources matched the changing contexts and related options and constraints.

This example suggests that the impact of social change on the individual depends on the context and the person as well as on the way both correspond and interact with each other. However, more detailed studies are needed concerning how external and internal factors affect human development and induce resilience or proneness to risk in times of social change. In the following section, contextual factors and person factors are examined in more detail with respect to their roles in the process by which social change affects individual development.

\section{Contextual Factors: Mediators and Moderators}

\section{Context as Multifaceted Variable}

Social change may be studied at the level of social context (e.g., changes in the labor market), at the level of individual behavior changes, or in terms of the relation between the two. Changes at the macrolevel of society (e.g., structural changes such as an increase in unemployment) may affect the person directly or indirectly. For 
example, information gained through the media or through interaction with other persons directly affects the individual. Indirect effects can also occur when a family member or the person himself or herself loses a job.

Contextual changes can be seen as both mediators and moderators of social change effects. To give an example, the family context may be a mediator of social change (e.g., when labor market changes lead to unemployment and economic hardship in the family, which in turn affect parent-child relations); the family context may also be a moderator of social change effects (e.g., when the family climate provides a buffer between external changes, such as dislocation, and the adolescent) in such a way that an otherwise negative impact of contextual changes is modified.

Here, we take the view that social change usually affects the individual indirectly; that is, filtered by multifaceted social contexts. Social contexts are understood here both as distal historical and cultural conditions and as proximal conditions (such as availability of social support in the family). The more distal social context and the more proximal social context may transmit social change. For the present purposes, however, we focus on the more proximal contexts affected by social change and their effects on human development.

Dynamic Approach. When looking for ways in which contextual factors transmit social change to the individual, one has to be aware of the ecological complexity of contextual variables and their different meaning in different cultural contexts. Also, one has to take into account that different components of social contexts may have different relevance for social and cognitive development at different periods of development (e.g., achievement demands in school, availability of attachment figures, etc.). By neglecting the process of individual development over time, a purely contextual approach clouds which factors have developmental implications. Instead, a dynamic model is needed that takes into account the social and psychological functions of contextual changes for individual development.

In line with this reasoning, the chapters by Elder and Russell and Brooks-Gunn, Schley, and Hardy in this volume demonstrate that one has to go beyond structural categories and static descriptions of context by differentiating between the following:

1. More distal contexts such as historical processes that allow us to place persons within their intergenerational histories (e.g., occupational career or life history of families and family members across generations).

2. More proximal contexts such as actual family prosesses.

These dimensions mediate and moderate effects of socioeconomic change on the development of children and adolescents. According to Elder and Russell (this volume), life course theory allows researchers to study individual development by locating a person in historical context and life stage, thereby focusing on the impact of historical, structural pathways and social strata and age-graded social 
trajectories (such as work or family). The focus on persons and their families takes into account history (through birth cohort) and the individual life course (through age). By interrelating these dimensions, the impact of biological and social factors (including the sociopsychological impact of birth cohorts and age strata) on individual development becomes another focus of attention. Reciprocal influences between social and developmental trajectories and mutual influences between people's life trajectories and their developmental processes (including choices and careers) are assumed.

Elder's position is that, to understand the developmental consequences of certain social changes, one should identify historical factors that account for changes in the life course. Both the proximal implications of social change (e.g., effects on family structure) and more distal consequences (e.g., labor market changes) for individual development are relevant. Therefore, Elder and Russell (this volume) differentiate between framing statements (proximal implications) and nested points of entry. This model allows us to measure the processes of change as an interplay between individual lives and a changing society. The advantage of this model is to "nest developmental analyses within a social change framework." Elder's studies make full use of birth cohorts in relating history to the life course and thus in relating historical and individual time. Therefore, Elder not only uses cohort-sequential designs but also studies variations within specific cohorts. Variations in family patterns (household economy, family relations, and strains) are viewed as linkages affecting children's developmental outcomes. This allows one to grasp the nested points of entry.

According to Elder's data, extreme hardship (e.g., economic depression) can strengthen certain psychological dispositions brought to the event such as emotional instability. Irritable men become more explosive and punitive in parenting, thus affecting the development of their children negatively. This can be a risk factor for children's development. This example also shows that changing societies do not necessarily affect the individual's development directly; rather, changes on the macrolevel are mediated and moderated by proximal conditions such as microlevel contextual factors and individual transitions.

Social Resources. During the life course, different aspects of the environment are important for the socioemotional and cognitive development of the person. In early childhood, attachment figures will be influential owing to their capacity to fulfill the child's basic needs for security and emotional bonding (Bowlby, 1969). Therefore, a critical question for effects of social change on early child development is whether and how the emotional availability of attachment figures (like the parents) is affected. During later development, multiple social agents will be important, such as siblings, peers, and adults. Accordingly, more has to be known about the psychological relevance of changes in the social environment over the course of development, especially with regard to close relationships and social resources. 
Family. Social support in the family modifies risk factors and provides a protective influence on children's development. In their study of Iowa youth, Conger, Conger, Elder, Lorenz, Simons, and Whitbeck $(1992,1993)$ demonstrated a close association between objective family hardship and increased risk of parental depression, conflicts in marriage, and nonnurturing parental behavior (both parents). These outcomes, in turn, were associated with lower self-confidence, lower peer acceptance, and lower school performance in early adolescent boys. Elder and Russell (this volume) find the same pattern of relationships for displaced families (who lost their farmland). However, in the case of strong marriage bonds and effective problem solving by fathers, children of displaced families developed a positive self-image and suffered fewer developmental risks. Parents in emotionally strong marriages can counter stress and depressed moods more effectively, support a sense of self-efficacy, and serve as a model and a protective force for their children (Elder \& Shanahan, 1996). Similarly, a strong emotionally based family and child orientation seemed to increase the resilience of East German children and adolescents during the dramatic transformation in the economic, political, and social system following unification (Trommsdorff \& Chakkarath, 1996).

The wider sociocultural and political context in which families are living should also play an important role in their responses to social change. For example, after unification, families in West Germany were more stressed by the economic depression and suffered more in the quality of family interaction compared with families in the East (Hofer, Kracke, Noack, Klein-Allermann, Kessel, Jahn, \& Ettrich, 1995). Although the families from different German regions presumably met objectively similar economic deprivations, they experienced these deprivations in different socioeconomic contexts and on the basis of quite dissimilar life histories. Thus, the same historical change had differential consequences.

Peers. The wider social network, especially peer relations, should also provide important mediating variables influencing the experience of change for children and adolescents. However, inter- and intracultural differences with respect to the relevance of peers for adolescents' development are also to be taken into account. In the former German Democratic Republic, peers had an important function in the socialization of children and adolescents (Schmidt, 1996), for nearly every child and adolescent joined well-organized peer groups (Junge Pioniere). Presumably, the breakdown of these youth groups negatively affected the sense of social integration, support, and control among East German adolescents, and some data suggest that this may have resulted in developmental risks (e.g., Zinnecker \& Silbereisen, 1996). For example, East as compared with West German adolescents tend to prefer more aggressive behavior in cases of frustration; and East German females hold more pessimistic expectations for the future (Trommsdorff \& Kornadt, 1995). 
However, contextual factors alone cannot predict individual development in changing contexts. Rather, it is necessary to specify what the individual's resources are in order to analyze how well environmental changes and individual resources match each other.

\section{The Subjective Experience of Social Change}

Besides social resources in the family and in the peer group, specific individual resources such as cognitive, social, and emotional dispositions are the basis of a person's competencies, values, and goals and influence his or her way of negotiating social change. On the basis of prior socialization and developmental experiences, a person has built up certain options in the life course and certain competencies that serve as psychological resources. These mediate the way in which "objective" changes are experienced (e.g., as gains or losses, as threats or promises) and the way these changes activate and possibly modify individual values, beliefs, and goals, which, in turn, affect further development (See Figure 1). Thus, diversity in development when experiencing social change is not only related to contextual factors but also to the developmental status of the individual, including competencies and patterns of beliefs that are used to interpret environmental changes and that affect the person's abilities for coping. Moreover, interaction effects between contextual and personal factors are to be expected.

Empirical studies have shown that children growing up with a sense of self-worth and a belief in self-efficacy are better able to cope with economic deprivation. Elder, King, and Conger (1996) showed that children from Iowa farm families grew up with close emotional ties to the family and felt that their parents viewed them as significant persons who were important for the family enterprise. Farm as compared with nonfarm children were more aware of their family responsibility, spent more time with family and less with peers, and were more involved in communal activities; also, they showed lower vulnerability to materialistic and hedonistic values. The authors explain these differences as an effect of farm children's personal resources, which are seen as a result of their socialization experiences, including more intergenerational continuity, more feelings of interdependence, and less individualization. This study supports our hypothesis that sociopolitical and economic changes are experienced differently and have differential consequences that depend on one's personal and social resources.

\section{Subjective Beliefs and Goals}

Over the course of development, a person has built up certain individual resources such as a specific "internal working model" and related belief systems (including beliefs in self and control). These resources filter the subjective perceptions and evaluations of events, including changes in the environment. The "inner working 


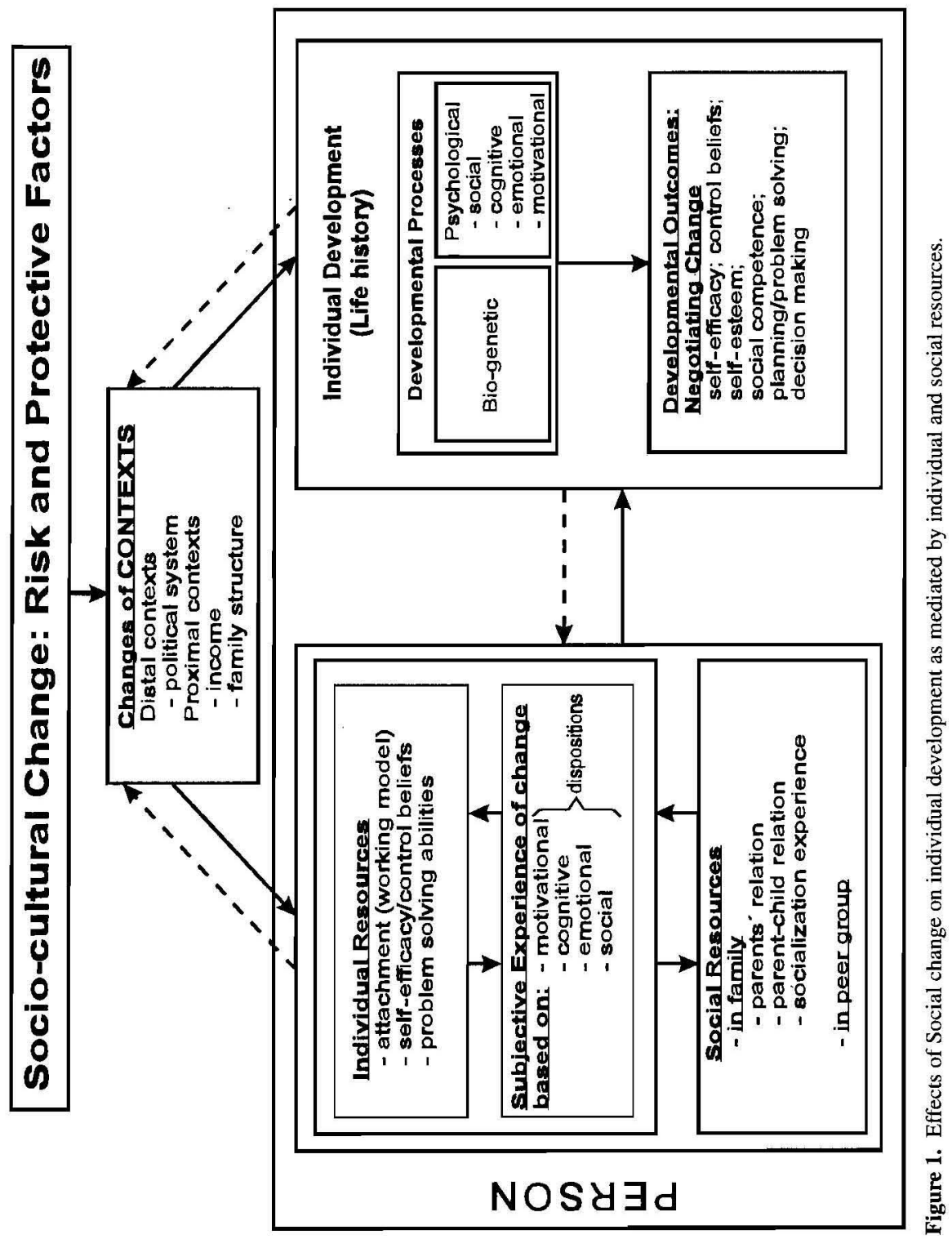


model" (Bowlby, 1969) is assumed to provide a basis for the person's belief system that serves to interpret oneself and the environment and the relation between them in a more positive or negative way. The same kinds of events could be subjectively experienced in very different ways, depending on the person's underlying belief system and internal working model. One's subjective experience of, and reactions to, changing events may serve either as a buffering factor or a risk factor in further development, implying either chances or an accumulation of risks in response to negative events such as an economic depression (See Figure 1).

Individuals act on their own development by setting goals (and disengaging from goals), by planning for achievement of these goals, and by carrying out the respective decisions. Certain changes may imply serious problems when previously established goals and related planning are disrupted. Some goals seem more difficult to achieve, whereas other goals (e.g., to pursue a certain career) seem to be completely blocked by ongoing changes (e.g., changes in the labor market). However, it may also be that certain wishes are transformed into goals and come to be viewed as realistic future outcomes.

The setting of goals and the evaluation of previous goals (in the light of the effects of social change on one's distal and proximal environment) are closely related to a person's identity and self-esteem and, more specifically, to his or her control beliefs (self-efficacy) and future orientation (Bandura, 1995; Scheier \& Carver, 1985). These are part of the personal resources that affect the subjective experience of change (e.g., the degree of stress due to the perceived difficulty of achieving one's previously set goals) and also the way of actually dealing with such experience. Effective coping consists of reorganizing one's goals, values, attribution preferences, control beliefs, and planning behavior.

\section{Scheduling of Changing Contexts and the Person's Developmental Transitions}

So far, we have dealt with the role of context and person and the interaction between them in individuals' development in times of social change. Additionally, the roles of timing of effects of social change and timing of biographical events have to be taken into account. Here, two aspects are relevant: First, individual variations in timing (e.g., adolescents' leaving home to take a job) can be a consequence of social change; second, individual variations in timing of biographical events can imply potential risk factors for further development under certain conditions of social change. Here, we will focus on possible implications of personal variations in timing of events for individual development in times of social change.

Some events in a person's biography, such as giving birth to a child as a teenage mother, can happen at a period in the person's development when the individual is not yet "developmentally" prepared. Normally, a match between new roles and personality development is secured by providing the necessary contextual conditions 
and by stimulating anticipatory socialization, training, or other planning activities related to the new developmental tasks. However, the scheduling of events in times of social change can have problematic effects, especially in the case of multiple transitions (e.g., starting a job, having a child). Multiple transitions need a certain synchrony that may be disturbed by unexpected events. By disrupting this synchrony and contributing to off-time transitions, social change can contribute to developmental risk.

The "off-time" scheduling of events and new roles can induce stress and risk. This can lead to self-perpetuating disadvantages in further development and may even affect the next generation. In their longitudinal studies on early childbearing, Brooks-Gunn and Furstenberg (1987), and Holmbeck, Paikoff, and Brooks-Gunn (1995) demonstrated that children of teenage mothers perpetuate teenage parenthood and long-time welfare dependency from one generation to the next. Children of Black teenage mothers experience cumulative effects of multiple risks: They grow up in poverty, in a single-parent family, and they have less educated and less securely employed parents. One third of these teenage mothers' daughters also become teenage mothers (Brooks-Gunn et al., this volume).

When social change events occur in one's life course, the timing of such events may be a risk factor for some persons and an opportunity for others. As noted earlier, Elder and his coworkers demonstrated that for preschool children who grew up during the Great Depression, family economic hardship negatively affected their emotional development. In contrast, adolescents could profit from the Depression; they had already developed capacities to take over social responsibility in their families and had developed more self-confidence. Studies on effects of unification in East Germany also demonstrate that for some age groups the transformation was a risk factor, whereas for others it was an advantage. For example, East German males born around 1940 had a lower belief in internal control directly after unification than any other male group in East or West Germany (Trommsdorff, in press). Obviously, for a certain cohort (males around 50 year of age) the turmoil after the reunification turned out to be a risk mainly because of decreased chances for employment at this age and the related off-time disengagement from social roles and activities.

The developmental timing of events also affects social motivation in children (unpublished data). Immediately following reunification and 3 years later, preschool children and adolescents in the East showed more anger and aggression and fewer prosocial goals compared with those in the West; this pattern was not found for children of intermediate age, however. A longitudinal study demonstrated that this difference has now disappeared for the older children (Trommsdorff, Kornadt, \& Hessel-Scherf, 1998) but has remained stable for adolescents. It seems that East German children who experienced social change at an intermediate developmental age could negotiate such changes more successfully than either younger children or older adolescents, both of whom were confronted with multiple transitions in 
and outside their family (e.g., the normative transition from preschool to school and from school to the job market).

\section{Summary and Outlook}

To summarize, individual development in times of social change can be conceived of as either a risk or a challenge, depending on the individual's personal and social resources. Such resources are part of one's past experiences and present (social) context, including the timing of transition. Social change does not affect a person's development negatively unless individual and social resources of the person do not match the new environmental demands. The context of the person, the timing of events, the person's developmental age, and related social and individual resources can each constitute risk or buffering factors. The main factors predicting how persons negotiate social change are the historical and sociocultural context, on the one hand, and the proximal context of family and social relationships, in combination with the individual resources and the scheduling and duration of events, on the other; these conditions allow us to predict how social change confers developmental gains or losses for the individual.

More precisely, a theoretical outline concerning development in changing contexts should specify which aspects of the social environment (social structure, economic conditions, family environment) relate in which way to individual resources in the dynamic process of transitions (see Figure 1). The timing of events and their fit with individual and social resources will affect a person's subjective experience of such events and contribute to the way the person acts on his or her development. Even in the case of mismatch between new environmental demands and the person's resources, problems of accommodation and assimilation can reestablish a person's control, reduce possible risks, and increase the person's potential for later coping with even more demanding changes in the environment. Therefore, further research should take into account processes of individual development in changing contexts.

In conclusion, future studies on social change and individual development should focus more explicitly on how the person perceives and experiences specific aspects of ongoing social change. Here, the view is taken that subjective experience of social change depends on the timing of events and on the accumulation and duration of transitions. Also, it depends on social relations (in the family and with peers) and on individual resources as transmitted by the person's life history and past socialization experiences (in a specific cohort, as male or female, and at a specific developmental age). Therefore, the timing of the person's encountering specific events of social change at a specific constellation of his or her personal development-in-context is a relevant starting point for empirical research. Because individuals are confronted with social change at different points in the process of change and at different times in terms of their social roles and developmental stage, social change can turn out to be a risk factor or a growth-fostering challenge for further development. 


\section{References}

Bandura, A. (Ed.). (1995). Self-efficacy in changing societies. Cambridge, England: Cambridge University Press.

Bowlby, J. (1969). Attachment and loss: Vol. 1. Attachment. New York: Basic Books.

Brooks-Gunn, J., \& Furstenberg, F. F. (1987). Continuity and change in the context of poverty: Adolescent mothers and their children. In I. J. Callagher \& C. T. Ramey (Eds.), The malleability of children (pp. 171-188). Baltimore: Brooks.

Conger, R. D., Conger, K. J., Elder, G. H., Lorenz, F. O., Simons, R. L., \& Whitbeck, L. B. (1992). A family process model of economic hardship and adjustment of early adolescent boys. Child Development, 63, 526-541.

Conger, R. D., Conger, K. J., Elder, G. H., Lorenz, F. O., Simons, R. L., \& Whitbeck, L. B. (1993). Family economic stress and adjustment of early adolescent girls. Developmental Psychology, 29, 206-219.

Elder, G. H. (1974). Children of the Great Depression: Social change and life experience. Chicago: University of Chicago Press.

Elder, G. H., King, V., \& Conger, R. D. (1996). Intergenerational continuity and change in rural lives: Historical and developmental insights. Intemational Journal of Behavioral Development, 19 , $433-455$

Elder, G. H., \& Shanahan, M. J. (1996). Social change, youth and agency: A perspective on the life course. Unpublished manuscript, University of North Carolina.

Hofer, M., Kracke, B., Noack, P., Klein-Allermann, E., Kessel, W., Jahn, U., \& Ettrich, U. (1995). Der soziale Wandel aus Sicht ost- und westdeutscher Familien, psychisches Wohlbefinden und autoritäre Vorstellungen [Social change from the point of view of East- and West German families, psychological well-being and authoritarian beliefs]. In B. Nauck, N. Schneider, \& A. Tölke (Eds.), Familie und Lebenslauf im gesellschaftlichen Umbruch (pp. 154-171). Stuttgart, Germany: Enke.

Holmbeck, G. M., Paikoff, R. L., \& Brooks-Gunn, J. (1995). Parenting adolescents. In M. H. Bornstein (Ed.), Handbook of parenting: Vol. 1. Children and parenting (pp. 336-374). Mahwah, NJ: Erlbaum.

Scheier, M. \& Carver, C. (1985). Optimism, coping, and health: Assessment and implications of generalized outcome expectancies. Health Psychology, 4, 219-247.

Schmidt, H.-D. (1996). Erziehungsbedingungen in der DDR: Offizielle Programme, individuelle Praxis und die Rolle der Pädagogischen Psychologie und Entwicklungspsychologie [Conditions of education in the DDR: Official programs, individual practice and the role of educational and developmental psychologyl. In G. Trommsdorff (Ed.), Sozialisation und Entwicklung von Kindern vor und nach der Vereinigung. Beiträge zum Bericht "Individuelle Entwicklung, Bildung und Berufsverlaufe im Transformationsproze $\beta$ " der KSPW, Bd. 4.1 (pp. 15-171). Opladen: Leske \& Budrich.

Trommsdorf, G. (in press). Subjective experience of social change and developmental effects. In R. Silbereisen \& J. Bynner (Eds.), Adversities and constraints in the life course. Berlin: de Gruyter.

Trommsdorff, G., \& Chakkarath, P. (1996). Kindheit im TransformationsprozeB [Childhood in the process of transformation]. In S. E. Hormuth, W. R. Heinz, H.-J. Komadt, H. Sydow, \& G. Trommsdorf (Eds.), Individuelle Entwicklung. Bildung und Berufiverläufe. Berichte zum sozialen und politischen Wandel in Ostdeutschland, KSPW Bd. 4 (pp. 11-77). Opladen: Leske \& Budrich.

Trommsdorf,, G., \& Kornadi, H.-J. (1995). Pro- and antisocial motivation of adolescents in Eastern and Western Germany. In J. Youniss (Ed.), After the wall: Family adaptions in East and West Germany. New directions for child development, No. 70 (pp. 39-56). San Francisco: Jossey-Bass,

Trommsdorff, G., Kornadt, H.-J., \& Hessel-Scherf, M. (1998). Soziale Motivation ost- und westdeutscher Kinder [Social motivation of East- and West German childrent Zeitschrift für

Sozialisationsforschung und Erziehungssoziologie. 18, 121-136.

Zinnecker, J., \& Silbereisen, R. K. (Eds.). (1996). Kindheit in Deutschland: Aktueller Survey uber Kinder und ihre Eltern [Childhood in Germany: Current survey on children and their parents]. Weinheim, Germany: Juventa. 